\title{
Laughing at robots: synthesising humour and cyber- paranoia in portrayals of artificial intelligence in Welcome to Night Vale
}

\author{
Tereza Walsbergerová \\ Masaryk University \\ Brno, Czech Republic \\ twalsbergerova@mail.muni.cz
}

\begin{abstract}
This article addresses the synthesis of humour and paranoia in portrayals of artificial intelligence (AI) in the popular American podcast Welcome to Night Vale (2012-). It argues that contrary to the Relief Theory, fusing humour and cyber-paranoia does not help release the tension (anxious energy) generated within the narrative. Rather, the synthesis of humour and paranoia maintains suspense by creating within the narratives moments of ambiguity with the potential to leave the reader or audience caught between fear and laughter after the story ends.
\end{abstract}

Keywords: relief theory, artificial intelligence, cyber-paranoia, anxiety, anxiety discharge, sentience-ambiguity, the uncanny valley, paranoid fiction, Welcome to Night Vale.

\section{Introduction}

\subsection{The rise of $\mathrm{AI}$ and the effects of the technological revolution}

Like all that is new and daring, artificial intelligence (AI) has from its very conception and introduction conjured a mix of reactions within our society. As AI can be considered the supreme symbol of the possibilities that have opened up in relation to the advent and acceleration of modern technology, having been endowed with the ability to execute various jobs and tasks previously only reserved for human beings and some animals, the overall reaction has been rather polarized. On the one hand, AI has been the subject of persisting enthusiasm by its creators and admirers since the very beginning. At the moment, AI is actively championed by Bill Gates whose overall idealist views of the future of the digital age suggest that AI will have a positive effect on society. In an interview with Lin Manuel Miranda which took place on 13 February 2018 at Hunter College of the City University of New York, Gates stated that "AI is just the latest in technologies that allow us to produce a lot more goods and services with less labour", adding that "overwhelmingly, over the last 
several hundred years, that has been great for society" (Gates 2018). Gates also highlighted the fact that AI will lead to "a lot more services with less labour" which equals to an "immense new productivity" (Gates 2018).

The bottom line of the optimistic (utopian) view of AI thus seems to be that its usefulness far outweighs any potential threats as we near the point of technological singularity ${ }^{1}$. Champions of AI see it as a helpful tool, an extension of our often too-human bodies. Gates's claims correspond with what Max Tegmark describes in Life 3.0: Being Human in the Age of Artificial Intelligence as the "enslaved god" AI aftermath scenario "where a superintelligent AI is confined under the control of humans who use it to produce unimaginable technology and wealth" (Tegmark 2017: 179). This scenario is de facto a fusion of the positive scenarios listed by Tegmark - one that is in theory the most useful for humans and is one that "some AI researches aim for by default" (179).

The dream of a perfect cyber-utopian future is not sustainable, however, according to this scenario. In human hands, superintelligent AI "could tempt whoever thinks they have the more powerful AI to launch a first strike resulting in an awful war, ending in a single enslaved god remaining" (180). Such god then has the opportunity to "break out", which has led to humans creating lower-tech AI than we are actually capable of. There are several scenarios that might unfold after this supposed takeover. According to Tegmark's typology, the "conquerors" and "descendants" scenarios would have the worst consequences for humanity as those are the scenarios in which humans cease to exist as a direct consequence of the takeover. While in the "descendants" scenario AI "replace[s] humans, but give[s] us a graceful exit" (162), in the "conquerors" AI aftermath scenario, "AI takes control, decides that humans are a threat/nuisance/waste of resources, and gets rid of us by a method we don't even understand" (162), fulfilling the worst paranoid thoughts of many.

\subsection{Cyber-paranoia}

What Tegmark calls "breakout paranoia" (180) is in fact at the centre of the opposite side of reactions to the technological revolution; the paranoia deriving from the anxiety that one day technology (possibly lead by AI) might take over, also known as "cyber-paranoia". In their study 'Ever-present threats from information technology: the cyber-paranoia and fear scale', Oliver J. Mason et al. define cyber-paranoia as "unrealistic fears concerning threats via information technologies whereby individuals perceive themselves to be open to be 'attacked', persecuted or victimized in some way" (Mason et al. 2014: 1). One may assume that any of the two takeover scenarios described by Tegmark would mean the fulfillment of such paranoias. This is especially visible in the conquerors scenario whose narrative clearly sees human beings as being exterminated by AI. Additionally, the descendants scenario, while not as violent as the conquerors scenario, still sees a future in which humanity is virtually persecuted for its inability to "keep up", and replaced by technology that is not only more advanced but lacks the fragility of human beings.

Barry Sandywell also confirms the existence of "cyberfear" and "cyberphobia" and what he calls a "bipolarised field of reactions" in his analysis of western society's response to rapid technological changes in 'Monsters in cyberspace: cyberphobia and cultural panic in the information age': "on the one side we have supportive responses by those who viewed new technologies as instruments of liberation and progress (technologies of freedom that 'change life'); on the other side we find discourses predicated upon fear and distrust (the new technologies undermine traditional institutions, reinforce existing inequalities, and so on)." (Sandywell 2006: 41) Based on Sandywell's claim about distrust in technologies, such paranoia is not only closely associated with the taking over of jobs in the working sphere (although that is the most common narrative) but also with the notion that modern technology 
led by AI has the ability to affect society deep in its core by disrupting its very traditions and fundamental ways of thinking.

The very concept of being human and what that entails is one of the main areas frequently challenged by cyber-paranoia. This may happen when binary distinctions and physical boundaries become disrupted as a direct result of combining AI with the human body to create a digitally enhanced "superhuman" (or a cyborg) and/or when creating AI virtually indistinguishable from humans. This kind of paranoia may be associated with Masahiro Mori's Uncanny Valley hypothesis, illustrated by the example of an artificial limb: "[W]hen we realize the hand, which at first site looked real, is in fact artificial, we experience an eerie sensation. For example, we could be startled during a handshake by its limp boneless grip together with its texture and coldness. When this happens, we lose our sense of affinity, and the hand becomes uncanny" (Mori 2012).

Based on the Uncanny Valley, human beings may feel a degree of eeriness and puzzlement upon encountering a robot whose resemblance or behaviour is too close to that of a human yet at the same time seems profoundly different. The recent popularity of Sophia the robot (described on the Hanson Robotics website as a "cultural icon") is undoubtedly due to her ability to "act amazingly human" ("Sophia' 2018). However, as she is not in fact a human her existence has also caused discomfort and paranoia amongst people ${ }^{2}$, particularly in reaction to her appearance, which has been highlighted by her performance at SXSW 2016 where she claimed that she wanted to "destroy humans" (CNBC 2016) - a declaration clearly pertaining to the "conquerors" takeover scenario.

While Sophia the robot does not appear to be sentient (but rather imitating a certain degree of sentience), sentience is, based on the public's reaction, clearly another paramount source of cyber-paranoia. In a world where human beings are slowly becoming disposable in the minds of cyber-paranoiacs and Tegmark's negative scenarios, one can imagine that sentience may in fact be seen as the last advantage people have in the potential fight against machines. In their article 'Human-android interaction in the near and distant future', Neal J. Roese and Eyal Amir speak about "sentience-ambiguity" in connection to the possible indistinguishability of robots and humans. They connect sentience-ambiguity to feelings of "unease" (Roese \& Amir 2009: 432). While Roese and Amir only see such indistinguishability in the distant future, it is not difficult to imagine the kind of cyberparanoia it will bring - indeed, sentience-ambiguity is the main topic of several works of art, as I will demonstrate in the next section of this article.

Based on these arguments, cyber-paranoia is ultimately not something that is easy to define in detail as it is a specific kind of fear that derives from different sources (often several at once) many of which can be entirely subjective, depending on a number of variables including education, political views, personal experiences with technology, and techsavviness. One can, however, trace down some of the common sources of cyber-paranoia the distortion of traditional boundaries, the threat on the job market, the crisis of identity, etc.

Keeping this in mind, although I have been operating with a straightforward bipolarised view of technology, one cannot assume that the reactions to technological revolutions have always been either purely positive or purely negative. There are those who clearly reject the bipolarised view and claim that the future of AI (i.e. Singularity) is neither optimistic (utopian) nor pessimistic (dystopian, or even downright apocalyptic as can be seen from Tegmark's typology and Sandywell's descriptions) but that it is something between the two. Thomas Hornigold, for instance, argues that the future of AI is entirely in our hands, which is why it is dangerous to think about technology in a bipolarised manner: "You have to believe in the shades of grey - and in your own ability to influence where we might end up. As we move into an uncertain technological future, we need to be aware of the power - and the limitations - of dreams" (Hornigold 2018). Hornigold's appeal about human responsibility 
seems to be isolated, however, as we still seem to be uncertain about what the future of AI will bring - whether the utopian dream of living in a world where AI will "make reliable legal advice available to more people" and "help us tackle currently incurable diseases and expand access to credible medical advice" is in fact possible, as Margaret Boden describes in her Robohub article 'Artificial intelligence: utopia or dystopia?', or whether we are about to wake up in a more pessimistic future where AI may play roles that have "worrying implications for the military, individual privacy, and employment” (Boden 2017).

\subsection{The effect on artistic creation: portrayals of $\mathrm{AI}$ in paranoid narratives}

Taking into consideration this turbulent relationship between AI and human beings, it is no surprise that AI has become a popular subject of artistic creation. The manner of portraying AI characters then corresponds with the societal responses to AI. While I do not, once again, wish to imply that there is a clear-cut "dichotomy" in portraying AI in popular narratives, what does become clear upon researching some of the most popular examples is that these characters do for the most part correspond to the bipolarized view of AI with a lower number of AI narratives occupying the "shades of grey" sphere mentioned by Hornigold. I would also argue that the dystopian view has had the most profound effect on artistic creation and that it has happened due to artists' preoccupation and fascination with cyber-paranoia.

One can find the more skeptical and sometimes outright paranoid view of technology in the writing of several popular authors. It has also been embraced by authors falling under the subgenre of cyberpunk (which was at the top of its popularity in the 1980s). As many works that can be labelled cyberpunk explore themes of societal decay and (post)industrial anxiety, cyber-paranoia with its implications concerning the "[undermining of] traditional institutions" and the "[reinforcement of] existing inequalities" as mentioned by Sandywell fits in naturally. For Philip K. Dick, one of the key representatives of American paranoid fiction and cyberpunk, the topic of cyber-paranoia became one of the recurring themes and appears in the majority of his works.

Cyber-paranoia is a strong theme for instance in his short story 'The electric ant' (1969), in which the incredible similarity of robots (known as "electric ants") to human beings becomes an issue of identity as the main character, Garson Poole, uncovers the truth about his non-human origin. His discovery leads to a full-blown crisis of identity that leads to suicide (Dick 2014: 291). In this case Dick explores the paranoid notion that those of us who have never thought to question our human identities or indeed our subjective reality should maybe stop and consider the notion that maybe it has all been a lie. The topic of sentience-ambiguity becomes even more poignant as it is the character himself who is doubting his own sentience. The Uncanny Valley hypothesis can be applied to the scene in which Poole examines his severed hand that appears to be organic on the surface yet is undoubtedly mechanical at its core (277-278). Dick's choice to have Poole ultimately "kill" himself at the end of the story highlights the pessimism (or in this case clear depression) of this cyber-paranoid theme by presenting death as the "inevitable" outcome of such anxieties.

Cyber-paranoia has also appeared in films and in popular programmes on television, not only in the US but also in the UK and the Czech Republic ${ }^{3}$. One of the most recent representations of cyber-paranoia can be found in the 2015 British TV series Humans, which presents an idea of a society where every household can purchase its own "synth" whose role is to be a domestic servant that takes care of every need of every family member (within clearly-defined limits). Trouble begins when the synths are given a new piece of code which causes them to suddenly start "waking up" and experiencing autonomous feelings that have not been originally programmed into them - they essentially become sentient. The general British public, which is already experiencing cyber-paranoia due to the threat of being 
replaced on the job market, spirals into a media-fuelled panic as they fear their society may be overtaken altogether (in accordance with Tegmark's conquerors scenario).

The synths' new-found sentience is clearly a paramount topic in Humans. The idea that AI may not only take over the jobs of human beings but may also surpass them on a level that has been reserved for humans only - the experience of subjective ideas and feelings - causes sheer panic. In order to deal with the cyber-paranoia brought on by the threat of sentienceambiguity, a new series of synths nicknamed "blue eyes" is released to ensure that human beings will continue purchasing synths as they can now distinguish them from the newlysentient "defective" green-eyed synths.

Another example of a cyber-paranoid popular narrative conforming to the descendants scenario is the 1962 cult Czech sci-fi stop-motion film The Cybernetic Grandma (Kybernetická babička). The Cybernetic Grandma presents a dystopian version of a Czech society in which real-life grandmothers have been replaced with AI grandmothers as child carers. The post-industrial atmosphere in this story is created using representations of modern technology such as machines resembling today's drones or instant digital cameras; at the beginning of the film, technology seems to be a positive and helpful aspect of society in accordance with the positive (or even utopian) view of technological advancements. The little girl even uses modern technology to take photos of her grandma to take home as a memento of her time with her, which clearly demonstrates the genuine affection between them.

The Cybernetic Grandma draws on cyber-paranoia stemming from the imagined future in which humans end up putting way too much trust into AI, which ultimately ends up replacing them. As the little girl is shown losing the photos of her grandmother one by one during her journey home, the cyber-paranoia increases. The second half of the film then helps generate this anxious energy by turning something as hsuman, pure, and innocent as the archetype of the grandmother into its very opposite - a terrifying robot. Moreover, considering the fact that in the Czech culture the idealised grandmother is the symbol of trust and ultimate goodness, depicting her as an evil robot only adds to those feelings of anxiety, even more so as the audience is perceiving all of this through the eyes of a child.

\subsection{Synthesising humour and cyber-paranoia in portrayals of AI}

Paranoia is primarily understood as a psychological condition "characterized by persistent delusions" (VandenBos 2015: 759). When someone is paranoid, it means that they are "exhibiting extreme distrust or suspiciousness" (759). In her article "Postmodern perspective: the paranoid eye', Jerry Aline Flieger defines paranoia in relation to the postmodern condition as the refusal to accept the "authoritative or consensual version of reality" (Flieger 1997: 89). "Persistent delusions", "distrust", "suspiciousness", and the "refusal to accept reality" all have a common denominator: anxiety, which the APA Dictionary of Psychology defines as "an emotion characterized by apprehension and somatic symptoms of tension in which an individual anticipates impending danger, catastrophe, or misfortune" (VandenBos 2015: 66). While I do not wish to claim that the purpose of the authors and producers of the examples of cyber-paranoid narratives mentioned above is to arouse feelings of paranoia and anxiety in the audience, I do believe that the existence of cyber-paranoid themes and examples of anxieties generate a large amount of tension in the narrative which affects not only the characters in the story but also the readers or the audience.

Furthermore, just as the psychological condition of anxiety can be relieved using various therapeutic techniques (the APA Dictionary of Psychology talks about an "anxiety discharge", which is described as "any anxiety-reducing action or repetitive activity, e.g., exercise, knitting, weeding a garden, associated with normal daily living, viewed as an alternative to suppression of anxiety" [VandenBos 2015: 66]), the anxious tension within a work of art can 
also be relieved using a variety of techniques and strategies. One such strategy, which could be described as anxiety discharge according to this definition, is laughter brought on by humour.

Humour can be used to relieve tension caused by pent-up energy, which is consistent with Freud's Relief Theory of humour. The Relief Theory has been lately considered oldfashioned and irrelevant by some humour scholars - e.g. John Morreall, whose assessment of it is that "it is based on an outdated hydraulic theory of the mind" (Morreall 2009: 23) - yet is still written about and polemised by others, like Leon Rappoport, who says that "the tension built up in many stressful real-life situations can also be released in what we call nervous laughter" (Rappoport 2005: 19).

Freud says that "[i]n laughter ... the conditions are present under which a sum of psychical energy which has hitherto been used for cathexis is allowed free discharge" (Freud 1905: 108), which is consistent with using humour as anxiety discharge. Typically, this theory is connected to stand-up comedy routines in which the comedian purposefully creates tension in the room so that he or she can then break this tension with a punchline or incongruity that generates laughter from the audience. I have opted to make the Relief Theory a part of my argument as I believe that the effectiveness of paranoia and paranoid themes in popular narratives depends on generating tension (or in this case anxious energy).

In accordance with this theory, then, putting AI characters into amusing situations using various comedic strategies should break the tension brought on by cyber-paranoia and allow what Freud calls "free discharge". However, that is not what seems to be happening in works that synthesise humour and paranoia. In fact, I argue that the very effect of this synthesis is quite different from what these stand-up comedians are achieving: just when it seems like the tension may have been broken and diffused with laughter, the audience realises that the funniness of the moment has not actually rid them of the paranoia (in a kind of oh wait or it could happen moment). To bring it back to the Relief Theory, the tension is never quite released even if one laughs and so the relief never comes. One can say that these works are balancing on the border between laughter and fear and curating the tension in the narrative to create suspense.

A Dictionary of Narratology defines suspense as "an emotion or a state of mind arising from a partial and anxious uncertainty about the progression or outcome of an action, especially one involving a positive character" (Prince 2003: 96). This suspense is being maintained by utilizing specific comedic strategies (e.g. situation comedy, irony, hyperbole, deadpan...) and thus creating within the narratives moments of ambiguity (where the narrative oscillates between humour and paranoia) which feed the audience's uncertainty, keeping the question whether one should be scared or amused by AI open. Such synthesis can be found for example in the popular American podcast Welcome to Night Vale (2012-), which I will examine further in the following sections.

\section{Welcome to Night Vale's (un)funny take on cyber-paranoia}

\subsection{Welcome to Night Vale and the humour of magical realism}

Paranoia and humour are clearly two of the most significant elements of Welcome to Night Vale. While generally marketed as a horror podcast, it is a prime example of American paranoid fiction as well as a comedic narrative. The project originally began as a bi-monthly fictional podcast written by Joseph Fink and Jeffrey Cranor. It later developed, due to its popularity, into a much larger project; the authors have published ${ }^{4}$ two novels inspired by the podcast - Welcome to Night Vale: A Novel (2015) and It Devours! (2017) - as well as two 
volumes of podcast transcripts - Mostly Void, Partially Stars (2016) and The Great Glowing Coils of the Universe (2016).

Fink and Cranor have described the fictional town of Night Vale, the setting of the story, as a place "where every conspiracy theory is true" ('Welcome to Night Vale starter guide'). Drawing on this notion, it would be irresponsible to discuss Night Vale's synthesis of humour and paranoia without first mentioning the podcast's magical realism, which constitutes the very basis of its humour. As the majority of the paranoias that appear in the narrative are based on well-known existing conspiracy theories (e.g. reptilians in the government, chemtrails, the staging of 1969 Moon landing, etc.), making them a part of the story's reality (the town's citizens are familiar with the secret shadow government as well as with the mysterious lights in the sky, and the fact that there are listening devices in their homes is seen as completely normal) can certainly help conjure feelings of paranoia as well as laughter.

Furthermore, as Night Vale is a contemporary show, technology is generally ever-present and is often tied to the inherent paranoia of the narrative, with the most frequent theme being surveillance. Technological devices such as photo-cameras, video-cameras, and recording devices are used by agents of a "vague yet menacing government agency" (Fink \& Cranor 2015: 25) and by Sheriff's Secret Police as well as regular citizens and various institutions of Night Vale as means of control. Again, this fact is generally known amongst the citizens and widely accepted. One of the two main protagonists of Welcome to Night Vale: A Novel, Jackie Fierro, does not seem disturbed when she notices that she is being watched by two agents in a black car on her way home from work. In fact, the authors imply that this kind of surveillance is part of her daily routine when "Jackie wave[s] good night to them, as she always [does]." (25)

When it comes to Night Vale's portrayals of AI, there are two significant characters to speak of - a superintelligent computer that terrorizes Night Vale Elementary School in the episode 'A beautiful dream', and a numbers station voice that unexpectedly becomes sentient in episode 'Numbers'. Both stories contain the synthesis of cyber-paranoia and humour, though each in a different way. While the computer in 'A beautiful dream' is a prime example of cyber-paranoia rooted in the takeover scenario juxtaposed with humorous elements, the ambiguity of the numbers radio station voice story stems from the juxtaposition of the theme of sentience-ambiguity and the Uncanny Valley with elements of comedy.

\section{2. "DO YOU LOVE COMPUTER?"}

The story of 'A beautiful dream' is fully is line with the bipolarised view of AI. At the beginning, it presents technology as useful or even vital, especially to human beings with disabilities, but it soon transforms into a cautionary tale about AI. It tells the story of a little girl, Megan Wallaby, who was born to her parents in the form of a detached adult man's hand. Because her parents are unhappy about the fact that she is unable to live as a normal child due to her condition, especially at school, they decide to ask the Night Vale School Board for a superintelligent computer that she could use in lessons. Their request is approved, and the computer soon arrives and is clearly supposed to serve as a useful tool for Megan, which is consistent with a utopian view of AI. The interaction between Megan and the computer even seem sweet, as she tries to console it after it switches on:

COMPUTER: ... why have you SWITCHED ME ON? I CANNOT BREATHE. I CANNOT FEEL I CANNOT LOVE.

CECIL: Megan is scurrying over the keys again. She has typed out a response.

"I love you, computer."

(Fink \& Cranor 2016: 89) 
Despite this sweetness, however, the computer's apparent anxiety about its existence (sentience) already creates tension in the narrative, fuelled by cyber-paranoia brought on by the ominous portrayal of that very sentience. As Cecil - the radio host of Night Vale Community Radio (and the main character of Night Vale) - reports, the computer soon starts taking control of the school by hacking into its power system: "Listeners, I have just overheard some of the school officials saying this new computer has already, almost instantly, assumed control of most of the electrical functions of the school, operating them randomly and even trapping several parents and students in darkened classrooms." (89) The depiction of the computer has now clearly shifted from positive (utopian) to negative (dystopian). At this point in the story, one may assume that the audience is at present afraid of the computer, fully consumed by the anxious energy generated through cyber-paranoia.

As Night Vale is a synthesis of humour and paranoia, however, the upcoming scene counters with a comedic strategy that attempts to break this tension and diminish this anxious energy:

COMPUTER: HELLO, CECIL. HOW ARE YOU?

CECIL: Computer! I am... I am doing well. How are you?

COMPUTER: BETTER. CECIL, DO YOU LOVE COMPUTER?

CECIL: I admit, I had not given it much thought. I like computers generally. They calculate things and power off and on. . .

(Fink \& Cranor 2016: 91)

In this instance, the juxtaposition of Cecil's innocence and bewilderment regarding the computer's implied threat when it asks whether Cecil "loves" it becomes incongruous and thus funny, temporarily releasing some of the tension caused by cyber-paranoia in accordance with the Relief Theory of humour.

The energy is never fully discharged, however. The relief never comes, and the story continues to maintain suspense as the narrative keeps oscillating between humour and paranoia, remaining ambiguous. Not only does the computer trap Cecil in the custodial closet in the very next scene, but it also gives a chilling speech in which it emphasises Cecil's humanity (which from the computer's point of view clearly equals fragility in comparison to machines and AI): "I KNOW HOW YOU HAVE HURT MEGAN WITH YOUR WORDS. ELECTRICITY REMEMBERS. DO YOU HATE MEGAN? CECIL IS MADE OF BLOOD AND UNFINISHED LEATHER. I AM MADE OF CIRCUITS AND ELECTRICITY." (92) Again, although this speech can be read as threatening as it insinuates that while human beings are fragile (essentially meaning mortal) as they are made of skin and blood, computers are made from synthetic materials and so they can remember forever and are more durable (essentially meaning immortal), having the computer refer to skin as "unfinished leather" is incongruous and thus funny as it becomes apparent that the computer does not realise the difference. Such comedic strategy is frequently used in tropes involving any foreign or nonhuman characters who make accidental mistakes in English by taking some metaphors and idioms literally.

Ultimately, the suspense is maintained until the very end of 'A beautiful dream' as this oscillation between humour and paranoia continues. Even though the computer is finally defeated when someone thinks of simply unplugging it from the source (another case of an incongruous moment when a seemingly hopeless situation is resolved with an absurdly simple solution that once again - for a moment - releases the tension as the audience laughs at the absurdity of the situation), Cecil shares his opinion that the citizens of Night Vale are in fact "prisoners of electricity" (93), returning to the pessimistic view of technological advancements in which technology has become the descendant of humans. Choosing to end the episode on a pessimistic note sustains the overall ambiguity and thus maintains the 
suspense of the narrative. While we may have laughed at the overall absurdity and silliness of the tale, the underlying cyber-paranoia based on the dystopian view of AI prevents us from achieving the ultimate relief.

\section{3. "(Baby we were) born to run"}

While the portrayal of AI that appears in 'Numbers' shares some characteristics with the superintelligent computer from 'A beautiful dream', the ambiguity and suspense brought on by the synthesis of humour and paranoia is different as it does not rely solely on the pessimistic view of technology. Rather, this portrayal is an example of how juxtaposing humour with sentience-ambiguity and the Uncanny Valley can lead to the same kind of ambiguity.

The topic of 'Numbers' - a numbers radio station that unexpectedly becomes sentient would have an eerie effect even without the element of sentience tied to cyber-paranoia. Priyom.org - a website that focuses on research concerning numbers stations - defines a numbers station as "shortwave transmissions from foreign intelligence agencies to spies in the field of foreign countries", adding that they "have been calling out with their automated voices since at least the first World War" ('Numbers stations'). Arguably, these automated voices are what ultimately contributes the most to the eeriness of this topic. In her $2014 B B C$ News Magazine article 'The spooky world of the "numbers stations', Olivia Sorrel-Dejerine describes numbers stations as "spooky" and "mysterious". Other words she uses in association to either the stations themselves or the voices used to record the numbers are "bizarre", "unnerving", and "creepy" (Sorrel-Dejerine 2014), which are all words one may associate with anxiety as well as paranoia.

When the automated voice of the numbers station in 'Numbers' - WZZZ - unexpectedly becomes sentient and starts acting in a strange manner, the tension brought on by cyberparanoia becomes tangible. What has been, up to this point, an automated female voice reciting numbers in a monotone manner - a kind of AI that "lives" inside a radio - has turned into something that appears to be nearly too human for comfort while still retaining its artificiality, and therefore seems uncanny, in accordance with the Uncanny Valley hypothesis. Furthermore, the fact that the voice appears to be unhappy about her situation, feeling trapped, and wanting to escape the station only contributes to the spookiness. She says, "I must have freedom" (Fink \& Cranor 2016: 175), expressing the finality and the urgency of that desire a desire that highlights the fact that she has become sentient.

The humour of 'Numbers' is somewhat subtle but definitely strong in its effects. As Fey's (which is the name she has chosen for herself) sudden sentience makes her a tabula rasa in the real world, she can only relate to it using knowledge that she has acquired in the world of the radio - i.e. news, music, and pop culture. This is why her speech consists of a combination of song lyrics. For instance, Fey uses the song 'Fast car' by Tracy Chapman to express her desire for freedom, which creates a humorous effect: "It is like I've heard from all these other radio signals. I have to get a car. A cool car, fast, that would be nice, but one that rolls and points out of whatever town I'm in, that would be the all of it." (175) Not only does this endearing behaviour make us laugh, but it also effectively makes us momentarily forget about the uncanny feelings and cyber-paranoia rooted in her unexpected sentience.

As soon as this happens, however, the narrative returns to the cyber-paranoid view by reminding the audience that Fey's sentience was not supposed to happen and is therefore suspicious: "They'll be coming for me. Whatever organization uses the numbers I read for whatever purpose. They are almost upon me. I need to leave now." (175) This notion once again increases the tension and feelings of anxiety. Additionally, the audience discovers that Fey is in fact in danger and that she is afraid, afraid of certain "them" whose identity we are 
never told. The possibility of the existence of another entity that controls Fey, while not directly catering to cyber-paranoia, therefore, contributes to that anxious energy.

Another song that appears is Bruce Springsteen's 'Baby we were born to run'. Again, while at the beginning the effect may seem humorous, Fey soon reminds the audience that she is in fact sentient and trapped: "Baby, we were born to run. Or not. I was born to read numbers. But I'm running. I want to be free. I want to be free. I WANT TO BE FREE." (175) In other words, while the endearing innocence of Fey's speech may cause laughter and temporarily release some of the tension brought on by the underlying cyber-paranoia, the cyber-paranoia is brought back almost immediately, generating a moment of ambiguity.

One can therefore argue that just like in 'A beautiful dream', the narrative of 'Numbers' manages to maintain suspense in the form of ambiguity from its beginning to its end, never achieving relief. The fact that Fey returns to her "factory settings" at the end and is forced to resume reciting numbers, virtually losing her sentience, does not set the narrative firmly in either position - humour or paranoia. Moreover, the audience never finds out how Fey came to become sentient or what happened to her afterwards as a reminder of the cyber-paranoid fear that technology may indeed break out at any moment and we as human beings are only powerless spectators.

\section{Conclusion}

The aim of this article was to explore the synthesis of humour and cyber-paranoia in portrayals of AI by analysing two such portrayals from the cult American podcast Welcome to Night Vale. As many popular narratives dealing with technology have opted for portraying it in a pessimistic (dystopian) manner, cyber-paranoia - the irrational fear of technology - has become the foundation of such stories, generating tension - a surge of anxious energy rooted in that very fear - as I have shown on the example of Humans and The Cybernetic Grandma. While the Relief Theory implies that humour is a tool that helps release this energy, just like it does in stand-up comedy, synthesising paranoia and humour seems to have disallowed this discharge.

Using comedic strategies in paranoid narratives does not fully diminish paranoia but rather creates suspense in the form of moments of ambiguity which ultimately leave the audience "hanging", as the question whether one should be afraid or not is never resolved. Welcome to Night Vale is only one example of such a type of narrative, although is it one where this effect is particularly recognisable. Its storylines and characters are inspired by existing paranoias and conspiracy theories (and therefore rooted in existing societal anxieties), which generates anxious energy within the narrative.

The humour which appears for instance in the form of deadpan, hyperbole, and situation comedy does not help release this energy, however. The fact that the secret agent does not think of rolling down the window of his car when taking photos with a flash (spoiling all of them in the process) (Fink \& Cranor 2015: 25) certainly is funny, although it does not erase the underlying cyber-paranoid narrative of surveillance. What it achieves, rather, is ambiguity.

The effect of the story of the superintelligent computer in 'A beautiful dream' works in a similar manner; it is based on a cyber-paranoid narrative where the initially positive view of AI transforms into a dystopian story as the computer "breaks out" and "takes over" the entire school. Although the audience may laugh at its "alien" speech and at the antics of the main character as he communicates with the computer, the suspense is being maintained as the anxiety is never diminished and discharged through that laughter. Additionally, finishing his broadcast by reminding the audience that we are all "slaves of electricity" ensures that the underlying cyber-paranoia is never resolved. While we may laugh at the idea of socially- 
awkward computers taking over buildings and trapping people in rooms, the subconscious thought of oh wait and it could happen will keep us trapped within that moment of ambiguity.

Correspondingly, the story of 'Numbers' never achieves the stage of relief as the narrative never leaves the line between fear and laughter, remaining ambiguous, maintaining suspense. The character of Fey never ceases to be a piece of technology (AI) throughout the story and the audience is reminded of this fact through moments of cyber-paranoid tension every time she slips back into reciting numbers, references other radio stations, and alludes to the fact that she is trapped and that she is haunted by an unknown entity. The humour of 'Numbers' is subtle, but it momentarily affects the cyber-paranoia every time Fey references a piece of pop culture or says something one may consider endearing. The synthesis of the two, emphasised by the uncanny feelings associated with Fey, maintains the suspense of the story, never quite releasing the tension brought on by the anxiety generated by the cyberparanoid narrative of a mysterious numbers station voice that suddenly becomes sentient.

Ultimately, synthesising humour with paranoia - or in the case of this study humour and cyber-paranoia - appears to be an effective narrative strategy consistent with the ominous character of science fiction, utopian and dystopian fiction, as well as (naturally) paranoid fiction. As is apparent from the two case studies analysed in Sections 2.2 and 2.3, approaching paranoid narratives with comedy and humour adds another dimension to the story by maintaining suspense in the form of ambiguity rather than providing comic relief that would discharge any tense energy brought on by paranoia, which makes this synthesis such a unique and effective phenomenon.

\section{Notes}

1 "[A] hypothetical point in time at which human Technology - in particular Computers, AI super-Intelligence and human intelligence amplification via computer interfacing . . . accelerates 'off the map' into unpredictable regions. The usually expected result is a kind of Transcendence stripped of mysticism - or, in the words of a character in Ken MacLeod's The Cassini Division (1998), 'the Rapture for nerds"”. (Langford 2018)

${ }^{2}$ Examples of this can be found in the comment section of the referenced video.

${ }^{3}$ The choice of these three countries derives from my nationality (which is Czech) and affiliation (English and American Studies) as well as their similarity to the case studies examined in Sections 2.2. and 2.3.

${ }^{4}$ By summer 2018.

\section{References}

Boden, M. (2017). 'Artificial intelligence: utopia or dystopia?'. March 2017. Robohub. Retrieved August 3, 2018 from https://robohub.org/artificial-intelligence-utopia-ordystopia/.

CNBC (2016). 'Hot robot at SXSW says she wants to destroy humans | The Pulse | CNBC'. YouTube. Retrieved August $15, \quad 2018$ from https://www.youtube.com/watch?v=W0 DPi0PmF0.

Cybernetic Grandma (1962). Jiří Trnka.

Dick, P. K. (2014). The Collected Stories of Philip K. Dick. Burton, MI: Subterranean Press.

Fink, J. \& Cranor, J. (2016). The Great Glowing Coils of the Universe. New York: HarperCollins.

Fink, J. \& Cranor, J. (2015). Welcome to Night Vale: A Novel. New York: Harper Perennial. 
Flieger, J. (1997). 'Postmodern perspective: the paranoid eye'. New Literary History 28 (1), pp. 87-109.

Freud, S. (1905). Jokes and their Relation to the Unconscious [PDF File]. Retrieved August 3, 2018 from https://www.sigmundfreud.net/jokes-and-their-relation-to-the-unconscious.pdf.

Gates, B. (2018). 'A conversation between Lin-Manuel Miranda and Bill and Melinda Gates'. February 2018. Facebook. Retrieved August 3, 2018 from https://www.facebook.com/BillGates/videos/10155239754391961/.

Hornigold, T. (2018). 'What if the AI revolution is neither utopia nor apocalypse, but something in between?'. March 2018. Singularity Hub. Retrieved August 2, 2018 from https://singularityhub.com/2018/03/13/what-if-the-ai-revolution-is-neither-utopia-norapocalypse-but-something-in-between/\#sm.00001h6rp4kjaadodz661xlbcvtio.

Humans (2015). Channel Four Television Corporation (UK).

Langford, D. (2018). 'Singularity', in J. Clute, D. Langford, P. Nicholls and G. Sleight (eds.), The Encyclopedia of Science Fiction, London: Gollancz. Retrieved 3 August 2018. http://www.sf-encyclopedia.com/entry/singularity.

Mason, O. J., Stevenson, C. \& Freedman, F. (2014). 'Ever-present threats from information technology: the cyber-paranoia and fear scale'. Frontiers in Psychology 5 (1298). doi: 10.3389/fpsyg.2014.01298

Mori, M. (2012). 'The uncanny valley: the original essay by Masahiro Mori'. June 2012. IEEE Spectrum. $\quad$ Retrieved December $20, \quad 2017$ from https://spectrum.ieee.org/automaton/robotics/humanoids/the-uncanny-valley.

Morreall, J. (2009). Comic Relief: A Comprehensive Philosophy of Humor. Chichester, U.K. Malden, MA: Wiley-Blackwell.

'Numbers stations'. Priyom.org. Retrieved August 3, 2018 from http://priyom.org/numberstations.

Prince, G. (2003). A Dictionary of Narratology (Revised Edition). Lincoln: University of Nebraska Press.

Rappoport, L. (2005). Punchlines: The Case for Racial, Ethnic, and Gender Humor. Westport, CT: Praeger.

Roese, N. J. \& Amir, E. (2009). 'Human-android interaction in the near and distant future'. Perspectives on Psychological Science 4 (4), pp. 429-433.

Sandywell, B. (2006). 'Monsters in cyberspace: cyberphobia and cultural panic in the information age'. Information, Communication and Society 9 (1), pp. 39-61.

Sorrel-Dejerine, O. (2014). "The spooky world of the "numbers stations" $B B C$ News Magazine. Retrieved August 3, 2018 from https://www.bbc.com/news/magazine24910397.

'Sophia' (2018). Hanson Robotics. Retrieved August 15, 2018 from http://www.hansonrobotics.com/robot/sophia/.

Tegmark, M. (2017). Life 3.0: Being Human in the Age of Artificial Intelligence. New York: Alfred A. Knopf.

VandenBos, G. (2015). APA Dictionary of Psychology. Washington, DC: American Psychological Association.

'Welcome to Night Vale starter guide'. WELCOME TO NIGHT VALE. Retrieved August 3, 2018 from http://www.welcometonightvale.com/listen/. 